\title{
Smoke alarm installation and function in inner London council housing
}

\author{
Carolyn DiGuiseppi, Ian Roberts, Norma Speirs
}

\begin{abstract}
Aim-To determine the prevalence of and predictors for installed, functioning smoke alarms in council (public) housing in a low income, multi-ethnic urban area. Design-Cross sectional study. Setting-40 materially deprived electoral wards in two inner London boroughs. Participants-Occupants of 315 addresses randomly selected from council housing lists, with $75 \%$ response rate.

Main outcome measures-Installation and function of smoke alarms based on inspection and testing.

Results-39\% (95\% confidence interval (CI) $33 \%$ to $46 \%$ ) of council tenants owned a smoke alarm, $31 \%(95 \%$ CI $25 \%$ to $38 \%)$ had an installed alarm (of which $54 \%$ were correctly installed), and $16 \%$ (95\% CI $12 \%$ to $22 \%$ ) had at least one installed, functioning alarm. Alarms most commonly failed because they lacked batteries $(72 \%)$. In multivariate modelling, having an installed, functioning alarm was most strongly associated with living in a house versus a flat (apartment) (odds ratio (OR) $3.2,95 \%$ CI 1.1 to 10.0 ), having two resident adults versus one (OR $2.8,95 \%$ CI 1.2 to 6.5 ), and recognising stills from a Home Office television smoke alarm campaign (OR 2.4, 95\% CI 1.1 to 5.5).

Conclusions-Fires are a leading cause of child injury and death, particularly among those younger than 5 years of age and those in social classes IV and V. Smoke alarms are associated with a significantly reduced risk of death in residential fires, and are more protective in households with young children. Few council properties in a multi-ethnic, materially deprived urban area had any installed, functioning smoke alarms, despite a high risk of residential fires and fire related injuries in such areas. Effective methods to increase the prevalence of installed and functioning alarms must be identified.

(Arch Dis Child 1999;81:400-403)
\end{abstract}

Keywords: accident prevention; burns prevention and control; protective devices

Unintentional injuries are the leading cause of death among children aged 28 days to 15 years in England and Wales, and fire and flames are the third leading cause of these injury deaths. ${ }^{1}$ In 1996, fire and flame deaths accounted for $9 \%$ of all childhood unintentional injury deaths, the majority of these occurring in children less than 5 years old. ${ }^{1}$ The 1996 mortality rate from fire and flames among children aged $0-14$ was $0.4 / 100000$ population. ${ }^{2}$ More than half of fire and flame deaths among children occur in house fires, with children aged under 5 years accounting for nearly two thirds of these deaths. $^{2}$

There is a steep social class gradient in the risk of fire death, with death rates 15 times higher among children in social class V compared to social class $\mathrm{I}^{3}{ }^{3}$ This steep social class gradient in fire deaths is caused in part by differences in risk factors for the occurrence of residential fires, which include living in lone parent or low income households, rental accommodation, or homes in poor condition, and living in "multi-ethnic, low income areas" and "council estate areas with greatest hardship" (ACORN groups 17 and 16, respectively (A classification of residential neighbourhoods; www.caci.com)). ${ }^{4}$ Differences in smoke alarm ownership might also help explain the social class gradient in fire related deaths among children, since low income, lone parent, and rental households are also among those least likely to own a smoke alarm.

It has been suggested that the use of smoke alarms to prevent fire related injuries may be the single most effective strategy for injury prevention in children. ${ }^{6}$ Smoke alarms have been associated with a two thirds reduction in the risk of death when a residential fire occurs, and are more protective against death in fires involving young children. ${ }^{7}$ Over the past decade, an increasing prevalence of smoke alarm ownership in England and Wales has coincided with a substantial reduction in fire injury death rates among children. ${ }^{8}$ However, while child death rates from fire have declined by $28 \%$ and $5 \%$ in children in social classes I and II, respectively, in social classes IV and V they have increased by $18 \%$ and $39 \%$, respectively. ${ }^{3}$

In a 1995 Office of National Statistics survey, the prevalence of smoke alarm ownership in public housing $(73 \%)$ was the same as that in owner occupied housing $(72 \%) .^{5}$ Some local authorities have committed to installing alarms in all their housing, ${ }^{9}$ which may explain these data. However, not all local authorities have made this commitment. In addition, the national survey did not assess the extent to which smoke alarms in council housing were properly installed and functioning.

In inner London, the majority of local authorities do not routinely install smoke alarms in existing council housing (except as required by law or building regulations $\mathrm{s}^{10}$ ), primarily because of concerns about potential liability from the failure to maintain them once 
Table 1 Smoke alarm ownership, installation, and function in inner London council housing

\begin{tabular}{|c|c|c|}
\hline Characteristic & $\begin{array}{l}\text { Number/ number } \\
\text { of participants }\end{array}$ & $\%(95 \% C I)$ \\
\hline \multicolumn{3}{|l|}{ Ownership and installation (by inspection) } \\
\hline At least one smoke alarm present & $89 / 228$ & $39(33$ to 46$)$ \\
\hline At least one installed alarm & $71 / 228$ & $31(25$ to 38$)$ \\
\hline At least one correctly installed alarm & $38 / 228$ & $17(12$ to 22$)$ \\
\hline \multicolumn{3}{|l|}{ Reasons for incorrect installation } \\
\hline \\
\hline \multirow{2}{*}{\multicolumn{3}{|c|}{$\begin{array}{l}<30 \mathrm{~cm} \text { from walls, lights, } \\
\text { or corners: } 12 / 43(28 \%)\end{array}$}} \\
\hline & & \\
\hline \multicolumn{3}{|l|}{ In or near kitchen: $8 / 43(19 \%)$} \\
\hline \multicolumn{3}{|l|}{ None on bedroom level: $5 / 43(12 \%)$} \\
\hline \multicolumn{3}{|l|}{ Function } \\
\hline \multicolumn{3}{|l|}{ At least one installed alarm with } \\
\hline positive button test & $36 / 223$ & $16(12$ to 22$)$ \\
\hline \multicolumn{3}{|l|}{ At least one installed, functioning } \\
\hline alarm (positive smoke test) $\dagger$ & $37 / 225$ & $16(12$ to 22$)$ \\
\hline \multicolumn{3}{|l|}{ At least one correctly installed, } \\
\hline functioning alarm $\dagger$ & $21 / 225$ & $9(6$ to 14$)$ \\
\hline \multirow{2}{*}{\multicolumn{3}{|c|}{ Reasons for failure (all installed, }} \\
\hline & & \\
\hline \multicolumn{3}{|l|}{ Battery absent: $33 / 46(72 \%)$} \\
\hline \multicolumn{3}{|l|}{ Battery disconnected: $8 / 46(17 \%)$} \\
\hline \multicolumn{3}{|l|}{ Alarm malfunction: $4 / 46(9 \%)$} \\
\hline Battery dead: $2 / 46(4 \%)$ & & \\
\hline
\end{tabular}

^For a given alarm, there may be more than one reason for "incorrect installation".

†Testing refused or impossible because of ceiling height in three households; two alarms lacked test buttons.

$\ddagger$ For a given alarm, there may be more than one reason for "failure".

installed (personal communication with staff from the London boroughs of Camden, Hackney, Hammersmith and Fulham, Haringey, Islington, Lambeth, Lewisham, Newham, Tower Hamlets, and Wandsworth, the Royal Borough of Kensington and Chelsea, and the City of Westminster, 8-12 July 1999).

We inspected council housing in a multiethnic, low income urban area in inner London where the councils do not routinely provide smoke alarms, in order to assess the prevalence of installed and functioning smoke alarms.

\section{Methods}

From a sampling frame of the addresses of all council housing located in wards with Jarman underprivileged area scores ${ }^{11}$ of 20 or more (indicating substantial material deprivation) in the inner London boroughs of Camden and Islington, we selected 335 addresses using computer generated random numbers. We notified each selected household by post that a research physician would visit within two weeks to administer a home safety survey. The letter did not mention fire safety or smoke alarms. Between October 1998 and March 1999, repeated visits were made to each household until the survey was completed or refused, or until a minimum of three visits had been made, including visits on both weekdays and weekends and at varying times of day. After three visits we attempted to confirm current occupancy with neighbours and the local authority. Vacant and owner occupied residences were excluded.

We assessed self reported smoke alarm ownership, testing and maintenance, incidence of false alarms and fires, awareness of fire safety campaigns, and demographic information, based on previously tested questions from the British Crime Survey ${ }^{12}$ and the Office for Population and Census Surveys (OPCS) national surveys. ${ }^{13}$ Questions to test fire safety knowledge were drawn from Home Office fire safety information. ${ }^{14}$ We also assessed recognition of photographs provided by the Home Office from recent smoke alarm campaigns. The inspection and testing procedures were developed from information provided by the London fire brigade and by the Home Office, and included the use of canned smoke to test alarm function. ${ }^{15}$ We pilot tested the survey, inspection, and testing procedures in 15 council households.

We calculated exact binomial 95\% confidence intervals (CIs) for proportions using Epi-Info 6 software (Centers for Disease Control and Prevention, Atlanta, Georgia, USA, 1997). We used logistic regression to estimate odds ratios (ORs) and 95\% CIs for predictors of having an installed and functioning smoke alarm, using EGRET software (Cytel Software Corporation, Cambridge, Massachusetts, USA).

The Great Ormond Street Hospital/Institute of Child Health research ethics committee approved the study.

\section{Results}

Twenty addresses were vacant (18), owner occupied (one), or outside the study wards (one). Of 315 eligible addresses, 252 occupants $(80 \%)$ responded to at least one survey question, $235(75 \%)$ completed the survey (including four surveyed by telephone), and $228(72 \%)$ consented to inspection. Ten $(3 \%)$ refused any participation and the remainder (17\%) were never found at home. Most participants $(86 \%)$ had lived at their current address for more than two years. Adults aged 65 years or older occupied $32 \%$ of households, and children under 5 years old were present in $14 \%$ of households. There were, on average, 2.3 occupants per household.

One hundred and eight respondents (43\%, $95 \%$ CI $37 \%$ to $49 \%$ ) reported owning at least one smoke alarm, while 73 (31\%, 95\% CI 25\% to $37 \%$ ) reported owning at least one alarm for each habitable floor level (as is recommended by the Home Office). On inspection, 39\% (95\% CI $33 \%$ to $46 \%$ ) owned at least one alarm, but only $16 \%$ (95\% CI $12 \%$ to $22 \%$ ) had any installed, functioning alarms. Households with children aged less than 5 years old were more likely to have an installed, functioning alarm than were those without young children $(23 \% v 15 \%$, respectively), but this difference was not significant (OR 1.7, 95\% CI 0.6 to 4.7). Inspection and questionnaire results are shown in tables 1 and 2 .

We assessed the effect on having an installed and functioning smoke alarm of fire safety knowledge, awareness of fire safety and smoke alarm campaigns, household composition, type and size of accommodation, and duration of tenancy. In a multivariate model, living in a terraced or semidetached house versus a flat (apartment) or maisonette (OR 3.2, 95\% CI 1.1 to 10.0 ), having two adults versus one adult in the home (OR 2.8, 95\% CI 1.2 to 6.5 ), and recognising stills from a Home Office television campaign promoting smoke alarms (OR 2.4, $95 \%$ CI 1.1 to 5.5) were significantly 
Table 2 Smoke alarm maintenance, and fire safety knowledge and awareness among inner London council tenants

\begin{tabular}{|c|c|c|}
\hline Characteristic & $\begin{array}{l}\text { Number/ number } \\
\text { of participants }\end{array}$ & $\%(95 \% C I)$ \\
\hline Battery ever replaced ${ }^{\star}$ & $61 / 86$ & $71(60$ to 80$)$ \\
\hline Battery replaced within past year ${ }^{\star}$ & $50 / 86$ & $58(47$ to 69$)$ \\
\hline Battery test button ever pressed ${ }^{\star}$ & $51 / 86$ & $59(48$ to 70$)$ \\
\hline Battery test button pressed within last 4 weeks ${ }^{\star}$ & $28 / 86$ & $33(23$ to 44$)$ \\
\hline Alarm ever vacuumed* ${ }^{\star}$ & $16 / 86$ & $19(11$ to 28$)$ \\
\hline Alarm vacuumed within past year ${ }^{\star}$ & $16 / 86$ & 19 (11 to 28$)$ \\
\hline Any false or nuisance alarms (eg, from smoking) ${ }^{\star}$ & $58 / 86$ & $67(56$ to 77$)$ \\
\hline Any fire safety home improvements (other than alarm) $\dagger$ & $52 / 236$ & $22(17$ to 28$)$ \\
\hline $\begin{array}{l}\text { Knows correct first response to chip pan (exposed deep fat } \\
\text { fryer) fire }\end{array}$ & $210 / 236$ & $89(84$ to 93$)$ \\
\hline Knows correct first response to serious living room fire & $130 / 236$ & $55(49$ to 62$)$ \\
\hline Aware of any smoke alarm campaign & $120 / 235$ & $51(45$ to 58$)$ \\
\hline Aware of television smoke alarm campaigns & $106 / 235$ & $45(39$ to 52$)$ \\
\hline Aware of "National fire safety week" & $30 / 235$ & $13(9$ to 18$)$ \\
\hline Recognises Home Office television campaign stillsł & $79 / 231$ & $34(28$ to 41$)$ \\
\hline Recognises Home Office billboard campaign photograph $\ddagger$ & $144 / 230$ & $63(56$ to 69$)$ \\
\hline Any household fires in the past year & $9 / 235$ & $4(2$ to 7$)$ \\
\hline
\end{tabular}

^Among subjects reporting at least one installed smoke alarm.

$\dagger$ Fire extinguisher or blanket, escape ladder, replacement of electrical equipment, other changes (for example, rewiring, fire doors).

‡ Four participants surveyed by telephone did not view photographs; one participant refused to view the billboard campaign photograph because of its content.

associated with having an installed, functioning alarm. Other factors included in the model were also associated with alarm function, but with imprecise effect estimates. These included exposure to a workplace fire safety programme (OR 2.7, 95\% CI 0.3 to 35.1), having heard of any television smoke alarm campaigns (OR $0.4,95 \%$ CI 0.2 to 1.1 ), having children aged less than 5 years in the home (OR 2.3, 95\% CI 0.7 to 7.8 ), having a tenancy longer than one year (OR 2.1, 95\% CI 0.7 to 6.5 ), having persons aged more than 64 years in the home (OR $1.9,95 \%$ CI 0.8 to 4.5 ), and having experienced a residential fire in the past year (OR 1.7, $95 \%$ CI 0.3 to 9.8 ). Number of floors and number of resident children were weakly associated with function and did not confound these estimates. There were no significant interactions. Fire safety knowledge, having made other fire safety improvements, and recognition of Home Office billboard smoke alarm campaign photographs were modestly associated with having a functioning smoke alarm, but were highly correlated with recognition of Home Office television stills and awareness of any television smoke alarm campaigns, and hence were not included in the model.

Among those owning smoke alarms $(n=82$ with complete data), the alarms were significantly more likely to be installed and functioning if the battery had been changed within the past year (OR 7.4, 95\% CI 1.8 to 30.2 ) or if the alarm had ever sounded (OR 3.5, 95\% CI 1.1 to 11.3 ), after taking into account fire occurrence in the past year, other fire safety improvements, awareness and recognition of television smoke alarm campaigns, and occupancy by adults aged 65 years and over. These estimates were not confounded by adjustment for fire safety knowledge, type or size of accommodation, duration of residence, number of resident adults or children, or occupancy by children under 5 years old.

\section{Discussion}

Less than $40 \%$ of council tenants in this materially deprived, inner London community owned a smoke alarm. Home inspections showed, moreover, that $20 \%$ of these alarms were not installed, and nearly half of installed alarms did not function. Thus, only $16 \%$ of council tenancy households had at least one installed and functioning smoke alarm. Nonfunction was most often caused by an absent or disconnected battery, rather than by alarm or battery failure. Batteries are commonly removed or disconnected in response to nuisance alarms and to the low battery warning sound. ${ }^{16}$ Among owners, having changed the battery within the past year strongly predicted alarm function, after adjustment for other factors associated with alarm function, including fire safety knowledge and awareness. Smoke alarm function was more likely in households where the occupants recognised photographs from Home Office smoke alarm promotion campaigns, suggesting that such campaigns may persuade some tenants who own an alarm to maintain it.

The local authorities in the two study boroughs do not routinely install smoke alarms in existing council housing, except as required by law (for example, for houses in multiple occupancy) or by building regulations (that is, in new construction or substantial renovation), ${ }^{10}$ and in special circumstances such as sheltered accommodation or major rewiring. This policy is consistent with that of nine of the 10 other inner London local authorities that we informally surveyed. Hence, our results are likely to be generalisable to other inner London boroughs, and to other urban, materially deprived boroughs with similar policies.

It is unlikely that many families living in poverty will identify either buying a smoke alarm or maintaining its battery as a high priority. Hence, in the absence of a commitment from the council, relatively few council tenants in materially deprived areas will have installed, functioning alarms. These results may help explain the steep social class gradient in fire related deaths among children. ${ }^{3}$ Because fire and flames are a leading cause of death among children, ${ }^{1}$ particularly among children in poverty, ${ }^{3}$ an increase in functioning smoke alarms in council housing could have important benefits for child health.

As part of its "National Contract on Accidents", the government has recommended smoke alarm installation to reduce accidental deaths. ${ }^{17}$ Promoting the need to have a properly maintained smoke alarm is a centre piece of the government's new strategy to reduce dwelling fire deaths by $20 \%$ by $2003 .{ }^{18}$ Most inner London authorities do not routinely install alarms because of cost and concerns about potential liability in the event that tenants fail to maintain their alarms. The installation of hardwired smoke alarms, which do not require annual battery change, is one potential solution. However, such alarms are relatively expensive to purchase and install (requiring an electrician), which may be problematic for councils stretching their funds to meet other obligations. Smoke alarms with 10 year batteries, which are less costly to purchase and install 
and also do not require annual battery changes, may be a more cost effective option. Addressing council concerns about liability-for example, through legislative protection-may also be effective. Since some councils provide alarms to all tenants despite these concerns (depending, for example, on release forms or tenant instructions), sharing information on methods to address liability concerns is another potential solution. There is an urgent need to identify effective and cost effective methods to increase the prevalence of installed, functioning smoke alarms in materially deprived council households.

We thank the participating council tenants, the London boroughs of Camden and Islington, and the Home Office. boroughs of Camden and Islington, and the Home Office. Home Office, and Camden and Islington Health Authority.

1 Office for National Statistics. Mortality statistics: childhood, infant and perinatal (series DH3 number 29). London: The infant and perinatal (series DH3

2 Office for National Statistics. Mortality statistics: injury and poiffice for National Statistics. Mortality statistics: injury and
peries DH4 number 21). London: The Stationpoisoning (series DH
ery Office, 1998:72.

3 Roberts I, Power C. Does the decline in child injury mortality vary by social class? A comparison of class specific mortality in 1981 and 1991. BMF 1996;313:784-6.

4 Budd T, Mayhew P. Fires in the home in 1995: results from the British Crime Survey. Home Office Statistical Bulletin 9/97. London: Government Statistical Service, 1997.
5 Roberts I. Smoke alarm use: prevalence and household predictors. Injury Prevention 1996;2:263-65.

6 Rivara FP. Traumatic deaths of children in the United States: currently available prevention strategies. Pediatrics 1985;75:456-62.

7 Runyan CW, Bangdiwala SI, Linzer MA, Sacks JJ, Butts J. Risk factors for fatal residential fires. $N$ Engl $\mathcal{F} \mathrm{Med}$ 1992;327:859-63.

8 DiGuiseppi C, Roberts I, Li L. Smoke alarm ownership and house fire death rates in children. F Epidemiol Community Health 1998;52:760-1.

9 House of Commons official report (Hansard). Smoke alarms. 30 ${ }^{\text {th }}$ March 1998.

10 ISCAIP Smoke Detector Legislation Collaborators. International smoke detector legislation. Injury Prevention. [In press.]

11 Jarman B. Underprivileged areas: validation and distribution of scores. BMF 1984;289:1587-92.

12 Hales J, Stratford N. 1996 British crime survey (England and Wales): technical report. London: Social and Community Planning Research, 1996.

13 Wilmot A, Dobbs J. National fire safety week and domestic fire safety. OPCS Omnibus Survey Publications Report 2. London: HMSO, 1994.

14 Home Office. Fire safety in the home: protect your home from fire. London: Home Office Communication Directorate, 1996.

15 Bosley K. Assessment of domestic smoke alarm tests (research report number 75). London: Home Office Fire Research and Development Group, 1997.

16 Marriott MD. Reliability and effectiveness of domestic smoke alarms (research report number 58). London: Home Office Fire Research and Development Group, 1994.

17 Anon. Our healthier nation: a contract for health. London: Stationery Office, 1998.

18 House of Commons official report (Hansard). Smoke alarms. 13th April 1999.

\section{Chronic pain from the appendix}

"Appendixes never grumble, they either shout or remain silent." That was the teaching I was brought up with and have taught to others, and it is probably regarded as almost axiomatic by many readers of this journal. Nevertheless attempts have been made from time to time to implicate the appendix as the source of chronic or recurrent abdominal pain. Now a surgeon in Cincinnati, Ohio has reported his extensive experience (Fournal of Pediatric Surgery 1999;334:950-4).

Over 12 years (1985-97) he operated on 52 patients with chronic right lower quadrant abdominal pain. Fifty of them were followed up for at least a year. All were judged before operation to have had "appendiceal colic" for at least a year, the interval between attacks being very variable. Appendiceal colic was diagnosed when, during an attack, the patient suffered abdominal colic and had tenderness at McBurney's point. There was usually severe pain making the patient curl up and writhe, and often retching or vomiting with facial pallor or flushing and a clammy skin or sweating. Food or drink characteristically exacerbated the pain and this was often used as a provocative test in the surgeon's consulting room.

The 50 patients ( 37 female) followed up were aged 5-20 years. Almost half of them (23) had attended the emergency department or been admitted to hospital because of previous episodes. Preoperative investigations such as abdominal ultrasound or gastrointestinal contrast studies proved unhelpful and were eventually abandoned as a routine. None of the removed appendixes showed acute or chronic appendicitis histologically. Seven were entirely normal and the most common findings in the rest were fibrosis (15), faecolith (13), and kinking (15). Forty nine patients were cured of their pain on follow up and the one remaining developed ureteric colic.

This experienced surgeon insists that appendiceal colic is a specific condition which can be diagnosed clinically and cured by appendicectomy. 